\title{
Analisis Pertanggalan Prasasti Wanua Tengah III
}

\author{
nfn. Trigangga
}

Keywords: inscription, dating, identification, transcription, transliteration, epigraphy

\section{How to Cite:}

Trigangga, nfn. Analisis Pertanggalan Prasasti Wanua Tengah III. Berkala Arkeologi, 14(2), 22-26. https://doi.org/10.30883/jba.v14i2.636

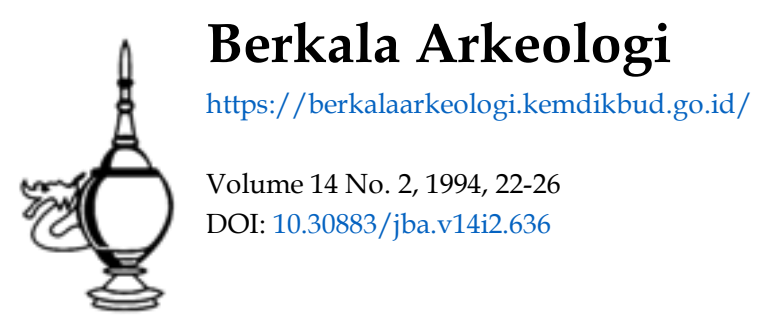

\section{(c) (1) (2) (2)}

This work is licensed under a Creative Commons Attribution-NonCommercial-ShareAlike 4.0 International License. 


\title{
ANALISIS PERTANGGALAN PRASASTI WANUA TENGAH III
}

\author{
Trigangga \\ (Museum Nasional)
}

\section{Pendahuluan}

Tidak dapat disangkal bahwa uraian sejarah indonesia kuna dari abad $V$ hingga XV $M$. sebaglan besar masih bertumpu pada sumber-sumber tertulis. Tanpa maksud meremehkan arti data non-tekstual, bahwa sumber tertulis seperti prasasti, naskah kuna dan kronik asing merupakan tulang punggung sejarah Indonesia kuna ada benarnya. Hal ini dapat dibuktikan bahwa daerahdaerah di Indonesia yang sedikit atau sama sekali tidak didapatkan sumber tertulis, historiografinya tidak banyak diketahui.

Prasasti sebagai salah satu sumber tertulis mempunyai kualitas yang sangat tinggi untuk merekonstruksi sejarah kuna, karena dari isinya dapat memberikan gambaran tentang berbagai hal yang sejaman dengan penulisan prasasti itu. Walaupun begitu, prasasti seperti halnya sumbersumber sejarah lain, perlu juga diuji kredibilitas isinya sebelum digunakan sebagai bahan penulisan sejarah. Pengujian yang dimaksud adalah melalui kritik ekstem maupun intern.

Salah satu bagian yang amat penting dari Isi prasastı adalah penyebutan unsur-unsur penanggalan. Bagian ini penting karena memberikan kerangka kronologi bagi penulisan sejarah. Kronologi yang dimaksudkan adalah upaya manusia untuk menempatkan kejadian-kejadian yang dianggap penting ke dalam urutan perjalanan waktu. Tanpa kronologi, uraian sejarah menjadi suatu kisah yang tidak bermakna dan kacau.

Jadi, dapatlah dipahami mengapa pembacaan unsur penanggalan yang tepat merupakan syarat yang mutlak. Kesalahan menuliskan atau membaca unsur-unsur penanggalan akan menghasılkan uraian sejarah yang anakronistik atau terjadı ketidaktepatan dalam mengisahkan peris tiwa sejarah yang terkandung di dalamnya.

\section{Analisis Pertanggalan Prasasti Wanua Tengah III}

Lebih darı satu dasawarsa yang lalu (1983) telah ditemukan sebuah prasasti lagi dari masa oemerintahan Raja Balitung. Prasastı Wanua Tengah III ), demikian nama prasasts itu, diambil dari nama daerah Wanua Tengah, yang dikukuhkan menjadi sawah sima bagi Sang Hyang Wihara di Pikatan. Prasasti yang berangka tahun 830 Ç ini menarik perhatian para sarjana untuk menelitinya lantaran di dalamnya terkandung kisah tentang peristiwa-peristiwa yang terjadi ratusan tahun sebelumnya. Beberapa pakar sejarah kuna yang pernah membaca dan menelitı prasasti ini antara lain Kusen (1984). Djoko Dwlyanto (1986), Boechari (1983).

Sebagai sumber sejarah kuna, prasasti ini mungkin dapat dipandang sebagaı suatu karya historiografi karena mengandung data historis yang diharapkan dapat mengisi dan melengkapı rekonstruksi sejarah Indonesia. Tidak banyak prasasti yang memuat data historis dari masa-masa sebelum prasasti itu ditulis, contohnya prasastı Harinjing tahun 849 Ç prasasti Pucangan tahun 963 \& prasasti Kudadu tahun 1216 \& dan lainlain.

Seperti telah disebutkan terdahulu bahwa bagian yang amat penting dari isi prasasti adalah penyebutan unsur-unsur penanggalan yang dapat digunakan untuk menyusun uraian sejarah secara kronologis. Akan tetapi karena prasasti-prasas. ti pada umumnya memuat unsur-unsur penanggalan dalam tarikh C maka periu disebutkan padanannya ke dalam tarikh yang berlaku umum, yaitu tarikh Masehi. Akan lebih baik lagi jika disebutkan juga hari, tanggal dan bulannya.

LC Damais (1951-1955) dalam salah satu karya ilmiahnya, Etudes d’Epigraphie Indonesienne IV: Discussion de la Date des Inscriptions, berhasil menyusun kembali perhitungan kalender dalam tarikh Ç yang disesuaikan dengan kalender tarikh Masehi. Buku yang menjadi acuan para epigraf ini memuat tabel konversi yang cukup banyak. Berkat penelitian Damais in banyak unsur-unsur penanggalan dalam prasasti dan naskah kuna yang tidak lengkap atau rusak dapat direkonstruksi dan dikonversikan ke dalam tarikh Masehı.

Meskipun hitungan yang dilakukan oleh Damais sangat akurat tetapi mungkin ada satu kendala dalam menggunakan tabel tersebut yaitu soal efigiensi waktu dalam menyelesaikan perhitungan. Ini dapat dimaklumi karena pada masa itu alat-alat hitung elektronik seperti kalkulator, apalagi komputer, belum dikenal secara umum. Dengan menggunakan komputer masalah konversi tarikh $C$ ke dalam tarikh Masehi dapat diselesaikan dengan cepat dan akurat. Bahkan mesin pintar yang canggih ini dapat digunakan untuk memeriksa kesesuaian unsur-unsur penanggalan dalam prasasti dan naskah, juga merekonstruksı unsur-unsur penanggalan yang rusak.

Berikut ini adalah hasil analisis komputer atas unsur-unsur penanggalan yang tercantum dalam prasasti Wanua Tengah III (sekaligus 
koreksı atas tulısan Djoko Dwiyanto berjudul "pengamatan terhaciap Data Kesejarahan dari Prasastı Wanua Tengah III tahun 908 M", dalam Pertemuan IImiah Arkeologi IV. Perlu diketahui bahwa kutipan prasasti di bawah ini berdasarkan transkripsı sementara yang dibuat oleh Boecharı (almarhum), yang sampai sekarang belum diterbitkan.

(I) I-BI ... ing Ç 668 asuji masa pancadasi sukla. pa pa ang. i2 adiri rakai panankaran. sira ta umarpanakan ikanang sawah haji lan I wanua tnah watak pikatan

Bagıan ini mengisahkan tentang awal pemerintahan Rakai Panangkaran. la memberikan sebidang tanah sawah milik raja yang terletak di Wanua Tengah untuk kepen-tingan biara di Pikatan. Jika semua unsur penanggalan itu dikonversi ke dalam tarikh Masehi hasilnya sebagai berikut:

1 sukla bulan Asuli tahun 668 Clatuh pada tanggal 19 September 746i 15 sukla bulan Asuji adalah tanggal 3 Oktober 7460 Awal siklus tanggal $22 \mathrm{Mel} 746$. Hari $\mathrm{Pa} \mathrm{Pa} \mathrm{Ang}$ harı ke 136 dalam siklus 210 hari, _atuh pada tanggal 4 Oktober 746 (besoknya).

(2) I.B4 ... ing Ç 706 cetra masa dafiamı sukla. pa ka sa. wara. angdiri rake panaraban. tann inulahulah , kanang sawah

Bagian ini mengisahkan awal pemerin-tahan Rake Panaraban. la tidak mengubah status tanah di Wanua Tengah yang telah menjadı hak biara di Pikatan.

Hasil konversi adalah sebagai berikut:

1 Sukla bulan Caitra tahun 706 S jatuh pada tanggal 26 Pebruarı 784: 10 sukla bulan Caitra adalah tanggal 6 Maret 784. Awal siklus tanggal 5 Oktober 783. Hari Pa Ka Sa, hari ke 154 dalam sıklus 210 harl. latuh pada tanggal 6 Maret 784.

(3) I.B4 Ing Ç 725 cetra $15 /$ masa sasti sukla. pa u su wara. mangdiri rakai warak dyah manara. sira ta umabak ikanang sima pjah rake warak sirang lumah i kelasa

Bagian ini mengisahkan awal pemerintahan Rakai Warak Jyah Manara. la mencabut hak biara atas tanah di Wanua Tengah. Dikatakan juga ia meninggal dan disemayamkan di Kelasa

Hasıl konversi adalah sebagai berikut:

1 sukla bulan Caitra tahun 725 c latuh pada tanggal 25 Pebruari 803 . 6 sukla bulan Caitra adalah tanggal 2 Maret 803 . Awal siklus tanggal 25 September 802. Hari Pa U Su, harı ke 160 dalam siklus 210 hari, latuh pada tanggal 3 Maret 80 (besoknya)
(4) I.B5 ... ing $\mathcal{}$ f 79 sriwana masa. caturdasi krsna wa pa su wara. mang /6/ diri dyah gula tann uwah atah ikanang sima ri kanang bihara i pikatan

Bagıan ıni mengisahkan awal pemerintahan Dyah Guia la tidak mengubah status tanah yang telah dicabut oleh Rakai Warak Dyah Manara

Hasil konversi adalah sebagaı berikut:

1 sukla bulan Srawana tahun 749 C jatuh pada tanggal 28 Juni 827 . 4 krsna bulan Srawana adalah tanggal 26 Julı 827. Awa! siklus tanggal 16 Juni 827 . Hari Wa Pa su. hari ke 41 dalam sıklus 210 hari, latuh pada tanggal 26 Juli 827.

(5) I.B6 . ing Ç 750 magha masa dwitiya sukla pa u a. wara. adirı rake garung anak sang lumah i tuk. sira ta umaluyakan ikanang sa M/wah sima i rikanang bihara I pikatan.

Bagian ini mengisahkan awal pemerıntahan Rake Garung, yaitu anak orang yang meninggal di Tuk. la mengembalikan status tanah menjadı hak biara di Pikatan

Di sini ada kesalahan dalam menulıskan unsur penanggalan wara khususnya sadwara (paringkelan). Di dalamnya tertulis $\mathrm{Pa} \cup \mathrm{A}$ seharusnya Wa $\cup A$. Hasil konversı adalah sebagaı berikut

1 sukla bulan Magha tahun 750 s jatuh pada tanggal 9 Januari 829,2 sukla bulan Magha adalah tanggal 10 Januarı 829. Awal siklus tanggal 9 Agustus 828 Hari Wa $\cup A$ hari ke 155 dalam sıklus 210 harı, Jatuh pada tanggal 10 Januari 829.

(6) I.B7 .. swasti Çwarsatita 751 marggasıra masa tithi caturdasi suklapaksa wu wa wr wara tatkala sri maharaja rakai garung umaluyaka 18/ n ikanang sawah haji lan I wanua tnah sima ni bihara i pikatan

I.B12 ... candrendriyagurowarse margga mase tathaiwa ca. caturthya suklapakse ca. wurukung mirajiwake //

Satu hal yang sangat menarık darı IS prasasti Wanua Tengah III adalah dikutipnya prasasti Raja Rakaı Garung secara utuh, balk dalam bahasa Javra Kuna maupun Sansekerta. Ini terbukti dari kalımat berikut:"

nahan Prasasti rake garung aruwahakan ikanang sawah sima ing bihara i Pikatan

"Rupa nya Rakal Garung pernah mengeluarkan maklumat sehubungan dengan kasus tanah di Wanua Tengah yang diabadikan ke dalam sebuah prasastı Prasasti itu dipaka sebagaı bukt untuk memperkokoh penetapan tanah sıma untuk biara dı Pikatan oleh Rakaı Watukura Dyah Balitung 
Jıka ditelıtı lebıh lanjut, IS। prasastı Rakai Garung yang dikutip ini aslinya berbahasa Sansekerta. Kemudian kutipan ini diterjemahkan ke dalam bahasa Jawa Kuna, mungkin maksudnya agar diketahui oleh orang yang tidak mengerti bahasa Sansekerta.

Unsur-unsur penanggalan yang terdapat dalam kutipan berbahasa Sansekerta dan terjemahan berbahasa Jawa Kuna tentunya harus sama. Angka tahun dalam kutipan prasasti beru-pa candrasangkala: candra bernilai 1 , indriya $=5$, dan guru $=7$ : dibaca menjadi 751 C. Inı berarti cocok dengan angka tahun dalam terjemahan prasasti itu. Kemudian, margga mase nama bulan ıni seharusnya ditulis marggasirsa mase. Selanjutnya, pada unsur penanggalan tithi ini terjadi ketidakcocokan Dalam kutipan prasasti tertulis caturthi, tetapi dalam terjemahan ditulis caturdasi. Setelah diperiksa ternyata yang benar adalah seperti yang tertulis dalam kutipan itu. Rupanya penuils prasastı (citralekha) salah menerjemahkan atau keliru menuliskan caturthi menjadi caturdasi Terakhir: wurukung mitrajiwake unsur penanggalan wara ini diterjemahkan menjadi Wu Wa Wr (Wurukung Wage Wrhaspati?

Hasıl konversı adalah sebagai berikut

1 sukla bulan Margasıra tahun 751 Ç jatuh pada tanggal 31 Oktober 829: 4 sukla bulan Margasira adalah tanggal 3 Nopember 829. Awal siklus tanggal 3 Oktober 829. Hari Wu Wa Wr hari ke 33 dalam siklus 210 hari. jatuh pada tanggal 4 Nopember 829 (besoknya).

\section{Al ing $\subsetneq 768$ phaiguna masa pratipada} krsna pa ka a wara man dirı rake pikatan dyan saladu. sira ta pindua ni lumabwur ikana sima

Sagıan ını mengısahkan awal pemerintahan Rake PIkatan Dyah Saladu. la dikatakan telah mencabut kembalı hak biara atas tanah perdikan itu

Hasıl konversı adalah sebagai berikut

1 sukla bulan Phalg Liıa tahun $768 \mathrm{C}$ latuh pada tanggal 19 Pebruari 847; $1 \mathrm{krsna}$ bulan Phalguna adalah tanggal 6 Maret 847. Awal sıkius tanggai 2 Januari 847. Hari Pa Ka A harı ke 64 dalam siklus 210 hari,_atuh pada tanggal 6 Maret 847

(8) II. Al if $/ 2 / 777$ jyesta masa pancami krsna ha wa sa wara mangdiri rake kayuwani dyah lokapala mateher tan uwah ikanang sima

Bagıan ını mengısahkan awal pemerintahan Rake Kayuwani Dyah Lokapala. la tidak mengubah status tanah perdikan yang telah dicabut kembali.
Di sinı ada kesalahan dalam menuliskan unsur penanggalan wara khususnya pancawara (pasaran). Di dalamnya tertulis $\mathrm{Ha}$ Wa $\mathrm{Sa}$, seharusnya Ha U Sa

Hasil konversi adalah sebagai berikut:

1 sukla bulan Jyesta tahun 777 Cs latuh pada tanggal 20 Mei 855.5 krsna bulan Jyesta adalah tanggal 8 Juni 855 . Awal siklus tang gal 20 Januari 855 . Harı $\mathrm{Ha} \cup \mathrm{Sa}$, hari ke 140 dalam siklus 210 hari, latuh pada tanqaal 8 Juni 855.

(9) II.A2 ... ing Ç 806 magha masa caturdası krsna. tung po bu wara. mangdirı dyah tagwas tan uwah atah ikanang sima

Bagian ini mengisahkan awal pemerintahan Dyah Tagwas Seperti pendahulunya Rake Kayuwangi, ia tidak mengubah status tanah perdikan tersebut

Hasil konversi adalah sebagai berikut:

1 sukla bulan Magha tahun 806 S jatuh pada tanggal 19 Januari $885,14 \mathrm{krsna}$ bulan Magha adalah tanggal 16 Pebruarı 885. Awa siklus tanggal 13 Desember 884. Harı Tung Po Bu, hari ke 67 dalam siklus 210 hari, latuh pada tanggal 17 Pebruari 885 (besoknya).

(10) II.A3 ... ing $\mathcal{C} 807$ asuji masa pancam krsnapaksa pa pa bu wara mangdiri rake panumwanan dyah dewendra. tan uwah atah ikanang sima

Bagian ini mengisahkan awal pemerıntahan Rake Panumwanan Dyah Dewendra. la, seperti juga raja pendahulunya, tidak mengubah status tanah perdikan

Di sini ada kesalahan dalam menuliskan unsur penanggalan wara, balk sadwara, pancawara maupun saptawara. Di dalamnya tertulis Pa Pa Bu, seharusnya Tu $\cup A$

Hasil konversi sebagai berikut:

1 sukla bulan Asujı tahun $807 \mathrm{C}$ jatuh pada tanggal 14 September $885,5 \mathrm{krsna}$ bulan Asuli adalah tanggal 3 Oktober 885. Awal siklus tanggal 11 Juli 885 . Harı Tu $\cup A_{+}$harı ke 85 dalam siklus 210 han latuh pada tanggal 3 Oktober 885.

(11) II.A3 ... i Ç 808 magha masa pancamı krsna wa po bu. $14 /$ wara. mangdiri rake gurunwa. nidyah bhadra. mingat rake gurunwant. I nkanang samankanatah phalgunna masa dwitiya krsna. paksa anayaka ta ikanang rat rikang kala

Bagian ini mengisahkan awal pemerıntahan Rake Gurunwani Dyah Bhadra. Sayangnya, di dalam praSasti tidak disebutkan bagaimana kebıjaksanaan raja ini mengena status tanah perdikan di Wanua Tengah 
Bahkan ıa diberitakan "mınggat" (dari kratonnya) pada tahun itu juga. Sepeninggal raja inı, kerajaan (Mataram?) mengalami masa vakum selama hampir 8 tahuin

Hasil konversi adalah sebagai berikut:

1 sukla bulan Magha tahun $808 \mathrm{C}$ jatuh pada tanggal 30 Desember 886; 5 krsna bulan Magha adalah tanggal 18 Januarı 887 Awal siklus tanggal 4 September 886. Hari Wa Po Bu, hari ke 137 dalam siklus 210 hari atuh pada tanggal 18 Januari 887

Kemudian berita tentang kepergiannya yang terjadi pada 2 krsna bulan Phalguna (tahun 808 Ç) itu jatuh pada tanggal 13 Pebruari 887

(12) II. A4 ... Ing Ç 816 marggasıra masa pancami krsna. tu pa bu. wara. mangdiri rake wunkal humalang dyah jbang. tamolah 15, atah kkanang sawah I wanua tnah i sri maharaja

Eagıan inı mengisahkan, setelah hampır 8 tahun dı Pulau Jawa tidak ada raja yang memerintah maka pada tahun 816 C tampillah Rake Wunkal Humalang Dyah Jbang sebagai penguasa baru Raja ini tidak mengubah status tanah itu, bahkan xemudian dıjadikan milik kerajaan

Di bagıan ını ada kesalahan dalam menuliskan unsur penanggalan wara khususnya saptawara (pekan 7 hari). DI dalamnya tertulis $\mathrm{Tu} \mathrm{Pa} B \mathrm{Bu}$, seharusnya Tu Pa Wr

Hasil konversı adalah sebagai berikut:

1 sukla bulan Margasira tahun 816 S Jatuh pada tanggal 2 Nopember 894; 5 krsna bulan Margasira adalah tanggal 21 Nopember 894. Awal sıklus tanggal 22 September 894. Hari iu Pa Wr hari ke 61 dalam siklus 210 hari latuh pada tanggal 21 Nopember 894.

(13) It.A5 ... Ing $९ 820$ jyesta masa tithi pratipadá krsna. tu po bu. wara i rikfi pangdiri sri maharaja rake watukura dyah balitung

Bagian ini meriwayatkan awal pemerintahan raja Rake Watukura Dyah Balitung, yang memerintah bersama Mahamantrinya, Rakryan I Hino Sn Daksottama Bahubajra Pratipaksaksaya

Hasil konversi adalah sebagai berikut

1 sukla bulan Jyesta tahun 820 C jatuh pada tanggal 25 April 898, 1 krsna bulan Jyesta adalah tanggal 10 Mel 898. Awal siklus tanggal 5 Maret 898 . Hari Tu Po Bu, hari ke 67 dalam siklus 210 hari. Jatuh pada tanggal 10 Mei 898.
(14) II.A6 . suklapaksa wis u so wara i rikan pisor alna nira kumonakan sang hyang $7 /$ dharmma bihara i jawa kabain swatantra

Bajian inı menyatakan bahwa Raja Balitung ketika itu memerıntahkan agar semua biara di Jawa berstatus otonom

Hasıl konversı adalah sebagai berikut

1 sukia bulan Margasıra tahun 826 C jatuh pada tanggal 11 Nopember 904, 2 sukla bulan Margasira adalah tanggal 12 Nopember 904. Awal sıklus tanggal 1 Julı 904 . Hari Wu U So hari ke 135 dalam siklus 210 hari. jatuh pada tanggal 12 Nopember 904.

(15) II.A7 if. 827 kartika masa tithi caturdası sukla. paksa pa po ang wara umungah sri maharaja rino kasatwan sanḱa il nyu gading

Bagiari in! menyatakan bahwa raja Balitung ketika itu memerıntanikan agar sawah perdikan milik bıљra di Pıkatan diubah dan dijadikan tanah lungguh raja

Hasil koriversi adalah sebaga berikut:

i sukla bulan Karika tahun 827 f. Jatuh pada tarigaal 1 Cktober 905, 14 sukla bulan Kartika adalah tanggal 14 Oktober 905. Awal siklus tanagal 25 A zustus 905 . Hari $\mathrm{Pa} \mathrm{Po}$ Ang hari ke 52 dalam sık! 210 harı, _atuh pada tang.gal 15 Oktober 905 (besoknya).

(16) II.A8 . ing 9830 asuj! masa padmanabha de ig/ wata. tith dasami suklapaksa tung pa wr. vara ; rika diwasa ni kanang sawah sima pikatann intwahakan / sang hyang wihara I pikatan

Bagian ini menyatakan bahwa pada tahun tersebut Raja Bal:tung memerintahkan agar sawah perdikan ıtu dikembalikan lagı menjadı hak milık bıara dı Pıkatan

Hasil konversı adalah sebaga! berıkut

1 sukla bulan Asull tahun 830 \& latun pada tanggal 30 Agustus 908 s 10 sukla bulan Asuil adalah tanggal 8 September 908 Awal siklus tanggai 10 Juli 908. Har: Tung Pa Wr hari ke 61 dalam sikius 210 harı latuh pada tanggal 8 September 908

\section{Penutup}

Prasasti Wanua Tengan Ill yang sarat dengan peristiwa-pertstiwa seiarah yang terjadi sebelum masa prasasti itu ditulis. merupakan sumber sejarah yang amat penting bagi rekonstrukg, sejarah !ndonesıa kuna. Sebagaı sumber sejarah bersıfat otentik karena menyebut peristiwa yang gejaman, tetapi sejauh mana kesahıhan prasast! ını dalam mengısahkan 
peristiwa-peristiwa yang terjadi sebelumnya masin harus diperkuat dengan bukti sumber lain sebagai pembanding (Djoko Dwiyanto 1986-101) Satu hal yang mengagumkan dari prasasti Inı adalah catatan peristiwa-peristiwa yang berkenaan dengan perubahan status tanah sawah di Wanua Tengah yang diuraikan secara kronologis, lengkap dengan unsur-unsur penanggalan seperti tahun, bulan, tanggal, hari dan pasaran Akan tetapi ada saja kesalahan ditemukan, entah itu salah tulis atau salah menentukan hari dan tanggal.

Berdasarkan analisis atas unsur-unsur penanggalan di dalam prasasti itu dapat digımpulkan bahwa kesalahan banyak terjadi daiam menuliskan unsur penanggalan wara, baik itu saptawara, sadwara, pancawara maupun ketiganya. Ini dapat dimalklumi karena lebih sukar mengıngat gabungan nama- nama wara yang berjumlah 210 dibanding mengingat namanama bulan yang cuma 12 atau tithi dan paksa yang berjumlah 30 .

Sebelum itu pernah ditemukan dua prasastı dengan nama yang sama, yaitu prasast Wanua Tengah I dan Wanua Tengah II. Kedua prasastı yang berangka tahun 875 C ini isinya sama. berasal dari masa pemerintahan Rakai Kayuwangı Pu Lokapala (Damais 1955:27 - 28)

\section{KEPUSTAKAAN}

Boecharı 1977 "Epıgrafı dan Sejarah Indonesı", Majalah Arkeologi, I, no.2, him. 1-38

Damais LC 1955 "Etudes d'Eprgraphie Indonesienne $N$. Discussion de la Date des inscriptions". BEFEO, tome XLVII, 7 - 290.

Djoko Dwiyanto, 1986. "Pengamatan ternadap Data Kesejarahan dari Prasasti Wanua Tengah III Tahun 908 M', Pertemuan Ilmiah Arkeologi .V (lla. Aspek Sosial Budaya). Jakarta, hal. 92 - 110

Kusen, 1984 "Temuan Baru dari Temanggung: Prasasti Raja Balıtung 830 Ç", Kompas (Minggu, 6 Mei) hal. IX

Trıgangga, 1993. Penggunaan Komputer untuk Epıgrafi: Perkiraan Pertanggalan Prasasti Tugu (belum diterbitkan) 